\title{
Community knowledge on HIV/AIDS and its relationship with sexual practices in Tabora and Igunga Districts, western Tanzania
}

\author{
G.M. NKYA ${ }^{1 *}$, C. SINDATO ${ }^{1}$, J. MCHARO ${ }^{2}$ and S.N. KIBONA ${ }^{1}$ \\ ${ }^{1}$ National Institute for Medical Research, Tabora Medical Research Centre, \\ P.O. Box 482, Tabora, Tanzania \\ ${ }^{2}$ National Institute for Medical Research, Headquarters, Box 9653, Dar es Salaam, Tanzania
}

\begin{abstract}
HIV/AIDS represents one of the critical challenges to human development in sub Saharan Africa. This study was carried out to assess the knowledge of HIV/AIDS and its relationship with sexual practices among communities in Tabora and Igunga Districts in western Tanzania. The study employed both qualitative and quantitative methods, which included interviews and group discussions. A total of 568 participants (female $=49 \%$; males $=51 \%$ ) were involved in the study. Two hundred and eighty-four of the respondents were adults ( $>25$ years) and 284 were youths of $12-25$ years. The results showed although the knowledge of the disease and its prevention was high (90\%) among the community, some gaps regarding the knowledge on modes of transmission were observed. About $17.2 \%$ of the respondents reported to have multiple sexual partners and only about half of the respondents reported the use of condoms. The level of education correlated significantly with the individual knowledge on HIV/AIDS $(P=0.003)$. There was no significant difference between urban and rural communities on their knowledge on HIV/AIDS $(P>0.05)$. Health education on HIV/AIDS prevention needs to be strengthened and improved to include cognitive behavioural interventions that emphasize attitude changes, negotiation skills and decisionmaking skills that could be effective in changing and maintaining safe sexual behaviour.
\end{abstract}

Key words: HIV/AIDS, knowledge, perceptions, Tanzania

\section{Introduction}

An estimated 40 million people around the world are living with human immunodeficiency virus (HIV) whereby, young people (15-24 years old) account for half of all new HIV infections worldwide. More than 6,000 become infected with HIV every day (UNAIDS, 2004). The AIDS epidemic is spreading fast in Africa in spite of the various efforts and resources put in place to prevent it (Muturi, 2005). In some countries AIDS mortality has overwhelmed the progress made in life expectancy achieved through control of other infectious diseases during the last half century (Timaeus, 1998).

The first AIDS cases in Tanzania were reported in Kagera Region in 1983, (URT2003). By 1987, all regions of the country had reported AIDS cases. In Tanzania, like other developing countries, HIV/AIDS is increasingly becoming the major underlying factor for hospital admissions (an estimated 50 to $60 \%$ of hospital beds are occupied by patients with AIDSrelated illnesses) and deaths, thus representing one of the critical challenges to human development (AIDS Policy Research, 2004). Constraints in the existing public health infrastructure are cited as major obstacles to scaling up HIV treatment (WHO, 2004).

The HIV/AIDS crisis is to a large extent a crisis of sexual behaviour. Unsafe sex is responsible for the large majority of HIV infections in sub-Saharan Africa (WHO, 2002). The AIDS epidemic will not subside until most people around the world know how HIV is transmitted, how to prevent infection and, if they or their partners are at risk, substantially change their sexual behaviour (UN, 2002).

Since there is no known cure for HIV/AIDS, behaviour change through health education is seen to be the most effective way of preventing its transmission. In Tanzania, health programmes have used preventive information tools such as mass media campaigns, information booklets, leaflets and posters to inform and educate the public about the disease and to promote behaviour change and healthy sexual practices (Rumisha et al., 2006; Mboera et al., 2006). However, little is known about the level of HIV and AIDS knowledge and sexual practices that increase the risk of contracting HIV infection or the sexually transmitted disease (STD) among the communities in western Tanzania. This study was therefore undertaken to assess the knowledge on HIV/AIDS among the communities in Tabora and Igunga Districts in relation to their sexual practices.

\section{Materials and Methods}

\section{Study area and study design}

The study was carried out between June and September 2005 in Tabora Urban and Igunga districts. Six streets and six villages were randomly selected from Tabora Urban and Igunga, respectively. Each 
study district was stratified into rural and urban strata to assess the level on knowledge of HIV/AIDS in the two settings. For the purpose of this study, people living within the diameter of $3 \mathrm{~km}$ from the district capital (Gongoni, Ng'ambo and Kipalapala streets in Tabora; Mwanzuki, Sokoni and Godawn in Igunga) were defined as urban dwellers while those living $8 \mathrm{~km}$ away from the district capitals (Tumbi, Itonjanda and Kalunde in Tabora and Chomachankola, Ulaya and Nanga in Igunga) were defined as rural dwellers.

The study populations were adults older than 25 years and youths of $12-25$ years old. Adults were randomly selected from these areas where one member of household was interviewed. Youths were randomly selected from their respective schools. Primary/Secondary schools were selected from the total number of schools by simple random sampling method. To avoid gender bias the sample size was divided into approximately equal number of females and males.

Community's knowledge on HIV/AIDS and practices was obtained through interviews using structured questionnaires and Focus Group Discussions. Eight focus group discussions involving eight to fourteen participants were conducted; four were for youth and four for adults. The collected data covered demographic information, knowledge on HIV/AIDS including transmission and prevention and sexual relationships.

\section{Data analysis}

Collected data were double entered and verified using Epi-Info 6 software. Data analysis was done using STATA version 7 (Stata Corporation, College Park, Texas) statistical software. Basic description of the data frequency distribution, cross tabulation and other basic statistics were analyzed so as to determine relationship between the variables.

\section{Results}

A total of 568 respondents $($ male $=292(51 \%)$ and female $=276(49 \%)$ participated in the study. Of these, 284 (136 females and 148 males) were adults and 284 were youth. Majority of the community interviewed (43.3\%) had completed primary school education, only $4.2 \%$ had no formal education, $22.3 \%$ of the respondents were in standard six or below and $30.1 \%$ had secondary education.

Ninety-eight percent (558/568) of the respondents had knowledge of HIV/AIDS. Education level was correlated significantly with the knowledge on HIV/ AIDS $(P=0.003)$, but age was not associated $(P=0.321)$. No significant difference was found in the HIV/AIDS knowledge of participants from urban or rural areas $(P=0.723)$.

Amongst those with no formal education, 1.4\% (7 in rural and 1 in urban mentioned other modes of HIV transmission including witchcraft, sharing of clothes or bed and eating food with an infected person (Table 1).

A larger proportion $(41.8 \%, \mathrm{~N}=568)$ of the respondents had one sexual partner; $17.2 \%$ had 2 or 3 sexual partners; $19 \%$ had more than three sexual partners; and $22 \%$ had no sexual partners. Twenty eight percent of the respondents reported to have not practiced sex and majority of them were the youths aged 12 to 15 years. Majority (55.2\%) of the youths aged 16-19 years reported to have practiced sex at least once among the group that has already practiced sex, followed by $20-25,14-15$ and $12-13$ year old age groups. Among those who had not practiced sex, the majority were of the age group 14-15 years followed by $12-13,16-19$ and $20-25$ years. It was reported that, the minimum age at which sex practice had been started was 13 years.

Table 1: Knowledge on Modes of Transmission of HIV/AIDS in Tabora and Igunga

\begin{tabular}{lcc}
\hline Knowledge on HIV transmission & \multicolumn{2}{c}{ Respondent s answers \% } \\
\hline & Urban $(\mathrm{N}=284)$ & Rural(N=284) \\
Unsafe sex & 100 & 99.3 \\
Blood transfusion & 63 & 40.6 \\
Contaminated instruments & 68 & 45 \\
Mother to child transmission & 61.3 & 44.4 \\
Witchcraft & 0.004 & 1.1 \\
Sharing common clothes or bed & 0 & 0.7 \\
Eating food with an infected person & 0 & 0.7 \\
\hline
\end{tabular}


Majority of the respondents knew that HIV can be prevented through safe sex, blood screening and abstinence (Figure 1). Amongst those who had practiced $\operatorname{sex}(\mathrm{N}=211), 59.2 \%$ of the adults and $44.8 \%$ of the youths had not used condoms during the past 3 months. The use of condoms was common among youth $(55.2 \%)$ than adults $(40.7 \%)$

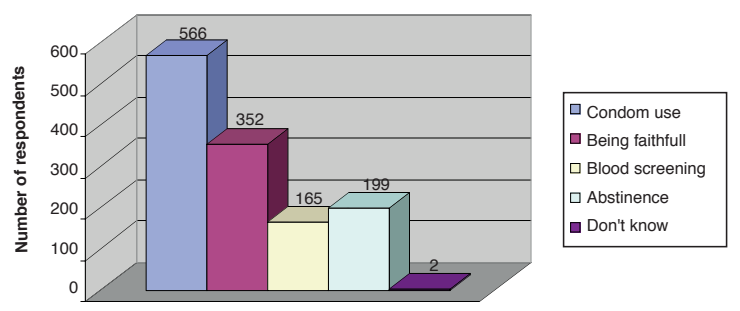

Figure 1: Number of respondents on HIV knowledge and prevention methods

During focus group discussions, the youths expressed their feelings in various styles and manner describing sex as natural relationship between opposite sexual partners. When asked about the use of condoms, a boy of 20 years old had these to say: "...condoms are not $100 \%$ safe, as viruses can pass through small pores" and that they are "more efficient in family planning rather than preventing $H I V$ transmission". Moreover, condom use was perceived to reduce sex pleasure." "Sex using condom is like eating sweets within its wrapper" A boy of 18 years old said.

Among the main reasons given by most youth for not using condoms included: i) church leaders are against the use of condoms and their use is ungodly; (ii) condoms are found only in the chemist and hospitals where few of them would like to visit; and that (iii) condoms sold in shops are only bought by few who are daring to withstand the shyness. A girl of 19 years old had this to say: "We do agree with my boy friend to use condom but the problem is who will buy them? Personally, I will never ever go to the shop to buy condoms because I feel shy to ask for the condom from the shopkeeper". Most of the respondents reported that, church leaders were against the use of condoms. This was likely to reduce the use of condoms within the community, as it was attested by a woman of 39 years old "While HIV/AIDS campaigns advocate for condom use, my church leaders advocate for faithfulness and condemn the use of condom".
When discussing on the sexual risk behaviours, participants had the view that, socioeconomic problems associated with poverty and lack of access to quality health care has directly or indirectly increased the risk to HIV infection among many individuals in their districts.

Each participant had something to contribute on prevention of HIV/AIDS which included abstinence, use of condoms, avoiding sexual relationship with emaciated and sick looking persons and change of behaviour by being faithful to your spouse. Most respondents suggested that the only possible way of controlling HIV transmission is to find means or drug that reduce sexual desire. This was attested by a man of 47 years old who added that: "...as a matter of facts, sexual desire is a biological need, abstinence is impossible. Scientist should look for a drug to reduce or postpone sexual desire".

\section{Discussion}

Our findings indicate that the majority of the individuals with primary school education were aware of HIV/AIDS, its transmission and prevention measure. This signifies that, education plays a major role in creating the awareness of HIV/AIDS among communities. These findings are consistent with results from studies carried out elsewhere (Peruga \& Celentano, 1993; Klepp et al., 2004; Rumisha et al., 2006). The community knowledge that sexual practice is among the major means of transmission has also been reported by other authors in sub-Saharan Africa (Aggleton et al, 1997; Klepp et al., 2004). Interestingly, in our study, urban residents were much more aware of other means of HIV/AIDS transmission other than sexual practices such as mother to child and blood transfusion. This suggests that there is need for health education programmes on HIV/AIDS to be strengthened to include all rural areas. Cultural beliefs, values and norms are likely to play a role in the spread of HIV among rural communities. Such risk factors have poorly been addressed by control programmes (Muturi, 2005).

The majority of the youths reported to start practicing sex at the age ranging from 16-19 years old. This calls for health education on HIV/AIDS to start at a relatively younger age to educate the youths on the preventive measures. As the youths grow towards this puberty age, they assume hormonal changes in their bodies, a factor making them to become more sexually active. Some previous authors indicated that, around the world each year, more than half of HIV incidences are between the ages of 15 and 24 and sixty two percent of infected youth are female (UNAIDS, 2002). Continual prevention outreach and education efforts are therefore required.

Basing on these findings it is concluded that although community awareness on HIV/AIDS 
prevention and control is high, the knowledge of relationship between transmission and control is poor. Health education on HIV/AIDS transmission and prevention should be strengthened and improved to include aspects of cognitive behavioural interventions that emphasize attitude changes, negotiation and decision making skills which could be effective in changing and maintaining safe sexual behaviour. It is recommended that further health education on HIV/ AIDS should focus schoolchildren information and prevention techniques being conveyed to them to fill the gaps in knowledge. Moreover, the community should be involved in identifying the risk behaviour, magnitude of the problem and possible solutions or disease prevention strategies in a participatory approach. This will enhance the adherence and sustainability of the health intervention programmes.

\section{Acknowledgements}

The authors would like to thank the Council Health Management Teams of the two districts for facilitating and organizing field data collection. We would like to thank Dr. Leonard Mboera for his comments on an earlier version of the manuscript. This study received financial support from the National Institute for Medical Research through the NIMR/CDC HIV/ AIDS project.

\section{References}

Aggleton, P. \& Warwick, I. (1997) Young People, Sexuality, HIV and AIDS Education. In: L. Sherr (ed.) AIDS and Adolescents. Amsterdam, Netherlands, Harwood Academic Publishers.

AIDS Policy Research Center (2004) Country AIDS Policy Analysis Project: HIV/AIDS in Tanzania.

James, S., Reddy, S.P., Taylor, M., Jinabhai, C.C. (2004) Young people, HIV/AIDS/STIs and sexuality in South Africa: the gap between awareness and behaviour. Acta Paediatric 93, 264-269.

Klepp, K-I., Mnyika, K.S., Ole-Kingori, N., Leshabari, M.T. \& Kissila, P.E. (2004) AIDS knowledge and risk perception in urban and rural communities in Arusha Region, Tanzania. East African Journal of Public Health 1, 40-47.
Mboera, L.E.G., Rumisha, S.F., Senkoro, K.P., Mayala, B.K., Shayo, E.H. \& Kisinza, W.N. (2006) Knowledge and health information communication in Tanzania. East African Journal of Public Health 3, 000-000 (in press).

Muturi, N. (2004) Communication for HIV/AIDS prevention in Kenya: social-cultural considerations. Journal of Health Communication 10, 77-98.

Peruga, A. \& Celentano, D.D. (1993) Correlates of AIDS knowledge in samples of the general population. Social Science \& Medicine 36, 509.

Rumisha, S.F., Senkoro, K.P., Ngadaya, E., Shayo, E.H., Mayala, B.K., Mtandu, R. \& Mboera, L.E.G. (2006) Community knowledge and information communication gaps on HIV/ AIDS in Iringa Municipality, Tanzania. Tanzania Health Research Bulletin 8, 101108.

Timaeus, I.M. (1998) Impact of the HIV epidemic on mortality in sub-Saharan Africa: Evidence from national surveys and censuses. AIDS 12 (Suppl. 1): S15-S27.

UN (2002) HIV/AIDS Awareness and Behaviour. United Nations Department of Economic and Social Affairs, Population Division. New York, UN. 29 pp. Available:http:// www.un.org/esa/population/publications/ AIDS awareness/. Accessed August 20, 2003.

UNAIDS (2002) Report on Young People and HIV/ AIDS: Opportunity in Crisis. Geneva, Switzerland.

UNAIDS (2004) Global Epidemic Report, 2004. Joint United Nations Programme on HIV/AIDS and World Health Organization, Geneva.

URT (2003) United Republic of Tanzania. Ministry Of Health Tanzania Mainland. Surveillance of HIV and Syphilis among Antenatal Clinic Enrolees: 2001-2002: National AIDS Control Programme, Dar es Salaam. <http:// www.developmentgateway.org/

WHO (2002) The World Health Report 2002. World Health Organization. Reducing Risks, Promoting Healthy Life. Geneva, 248 pp. $<$ http://www.who.int/whr/2002/. Accessed August 20, 2003.

WHO (2004) Summary Country Profile for HIV/AIDS Treatment Scale-up, 2004. World Health Organization, Geneva. 